\title{
CONSCIENTIZAÇÃO AMBIENTAL - PREPARANDO O FUTURO: RELATO DE EXPERIÊNCIA DE UM PROJETO DE EXTENSÃO EM PALESTINA DE GOIÁS (GO)
}

\author{
Maria Gláucia Dourado Furquim ${ }^{1}$ \\ Joyce Silva de Jesus ${ }^{2}$ \\ José Carlos de Sousa Júnior ${ }^{3}$ \\ Daniela Cabral de Oliveira 4
}

Resumo: As transformações oriundas das ações antrópicas nos últimos séculos imputam a toda a sociedade uma conduta e formação que considere a essencialidade do meio ambiente para a sobrevivência humana. Para tanto, a adoção de práticas pedagógicas que contemplem a Educação Ambiental desde as séries iniciais mostra-se indispensável. Assim, o presente estudo relata as atividades desenvolvidas em um projeto de extensão de área temática Meio Ambiente, do Instituto Federal Goiano - Campus Iporá, em Goiás, em parceria com a Escola Municipal Maria Izabel de Figueiredo, localizada em Palestina de Goiás, por meio da utilização de instrumentos lúdicos, identificando que os alunos demonstraram conhecer a importância dos recursos naturais.

Palavras-chave: Educação Ambiental; Formação Cidadã; Multiplicadores.

\footnotetext{
${ }^{1}$ Instituto Federal Goiano - Campus Iporá. E-mail: maria.furquim@ifgoiano.edu.br. Link para o Lattes: http://lattes.cnpq.br/2681775689273863

2 Instituto Federal Goiano - Campus Iporá. E-mail: joycekelly0911@gmail.com. Link para o Lattes: http://lattes.cnpq.br/6618783749056976

3 Instituto Federal Goiano - Campus Iporá. E-mail: josecarlos.junior@ifgoiano.edu.br. Link para o Lattes: http://lattes.cnpq.br/9146562480275155

${ }^{4}$ Instituto Federal Goiano - Campus Iporá. E-mail: danielacaboliveira@gmail.com. Link para o Lattes: http://lattes.cnpq.br/2113470352941981
} 
Abstract: The transformation of anthropic actions made in the last centuries ascribe to all the society a way of behave and an education that consider the environment as essential for the human race survival. Therefore, it is imperative to adopt pedagogical practices that include Environmental Education since primary school. In this way, it is reported in this study the developed activities from an extension project addressing the Environment as its subject, performed by the Instituto Federal Goiano - Campus Iporá, in the state of Goiás, in partnership with Escola Municipal Maria Izabel de Figueiredo, in Palestina de Goiás, also in the state of Góias. These activities were developed using playful instruments and they made it possible to identify that the students were able to recognize the importance of natural resources.

Keywords: Environmental Education; Citizenship; Multipliers.

\section{Introdução}

Nos setores sociais, intensificou-se o discurso acerca de temas como a sustentabilidade e a problemática ambiental. A limitada disponibilidade dos recursos naturais vem disseminando o que se chama de "onda verde" e fomentando iniciativas que promovem a ecoeficiência em organizações de diferentes portes e segmentos e, especialmente, mais conscientização acerca dos impactos das ações humanas sobre o meio ambiente, em termos de presente e futuro.

Porém, o atual modelo de crescimento econômico como norteador das relações sociais é incompatível com a preservação e regeneração dos serviços ecossistêmicos dos quais dependem as sociedades humanas para resguardar sua sobrevivência. Assim, são necessários novos hábitos e padrões de consumo que, simultaneamente, reduzem as imensas desigualdades sociais (nacionais e globais) e aumentam a ecoeficiência (ABRAMOVAY, 2012). Para tanto, torna-se crucial reinventar o processo de educação formal, mediante a adoção de materiais e técnicas que possibilitam o efetivo entendimento sobre as limitações do planeta. De acordo com Medeiros, Ribeiro e Ferreira (2017, s.p.):

A sociedade está desequilibrada e a única chance que temos é formando jovens de visões voltadas para as reais situações do mundo que vivemos, para que usufruam dos recursos naturais sem afetar sua estabilidade e conseguintemente nos afetar, e para isso o único caminho para alcançar esse tal avanço é a Educação Ambiental.

Um dos pontos que, na concepção dos autores, deve ser repensado refere-se à forma como a temática Educação Ambiental (EA) é trabalhada nas escolas públicas, comumente sem integrar disciplinas e de maneira descontinuada, ocasionando uma visão fragmentada da relação de interdependência entre ambiente-indivíduo. Ao mesmo tempo, é necessário 
inserir, nas atividades de ensino, a relação de causa e efeito caso não ocorram mudanças, assim como os desafios a serem imputados nos âmbitos econômico, social e ambiental.

Segundo Oliveira e Toniosso (2014), a EA constitui-se como mecanismo capaz de articular a relação entre a sociedade e a natureza, promovendo uma formação ampliada e cidadã, numa perspectiva preservacionista. Sendo assim, é preciso enfatizar que a escola assume um papel de suma importância para sensibilizar o indivíduo e, ainda, informar-lhe sobre a relevância de conservar o meio ambiente, visto que essa instituição consegue atingir uma centena de pessoas, as quais estão aptas a adotarem uma posição participativa e consciente com vistas à proteção do meio ambiente (VERDELONE et al., 2018).

Nesse contexto, as ações adotadas sob consoante abordagem socioambiental tiveram como objetivo promover atividades/experiências de Educação Ambiental na Escola Municipal Maria Izabel de Figueiredo, localizada no município de Palestina, em Goiás, integrando teoria e prática, a fim de despertar a consciência ambiental. Ao mesmo tempo, pretende-se que os alunos exerçam o papel de multiplicadores dessas informações no ambiente doméstico, conforme corrobora Narcizo (2009, p. 88): "Comportamentos ambientalmente corretos devem ser assimilados desde cedo pelas crianças $e$ devem fazer parte do seu dia-a-dia [...]".

\section{Metodologia da Pesquisa}

O município de Palestina de Goiás, no estado de Goiás, está situado a $280 \mathrm{~km}$ da capital Goiânia, possui uma população de 3.371 habitantes, com taxa de escolarização de 6 a 14 anos de idade de $98,6 \%$, duas escolas de Ensino Fundamental e um estabelecimento de Ensino Médio. As principais atividades econômicas para a formação do PIB municipal são, respectivamente, agropecuária, serviços e indústria, segundo os dados do último Censo 2010. (IBGE, 2019).

O tema proposto, "Conscientização Ambiental", foi selecionado em decorrência da relevância de atividades educativas específicas que trabalham a temática ambiental de forma articulada entre diferentes instituições de ensino. Nesse sentido, as ações realizadas decorrem de um projeto de extensão do Instituto Federal Goiano - Campus Iporá-GO, em parceria com a Escola Municipal Maria Izabel de Figueiredo, única instituição pública de Ensino Fundamental em Palestina de Goiás, a qual possui 189 alunos matriculados no turno vespertino, da pré-escola à $5^{a}$ série, sendo esse o público-alvo das atividades de Educação Ambiental. A equipe executora do projeto de extensão foi composta por discentes do Curso Superior de Tecnologia em Agronegócio, residentes no município de Palestina de Goiás, por egressos da escola parceira e por docentes das Instituições de Ensino envolvidas. O estudo realizado constitui uma pesquisa de natureza aplicada e objetivo exploratório e descritivo, que, segundo Gerhardt e Silveira (2009, p. 34), "objetiva gerar conhecimentos 
para aplicação prática, dirigidos à solução de problemas específicos. Envolve verdades e interesses locais".

Inicialmente, foi realizada uma pesquisa bibliográfica em livros, em manuais técnicos, em artigos e em sites, sobre temas correlatos à Educação Ambiental e práticas pedagógicas que permitiram definir as respectivas etapas a serem executadas: contação de história, vídeos infantis de curta metragem (Turma da Mônica "Um Plano para Salvar o Planeta" (disponível em: $<$ https://www.youtube.com/watch? $v=$ L3zaoUaHJhQ $>$ ), e a paródia da música Olha a explosão, produzida pela Aquarela Kids, "Ó o lixo no chão" (disponível em <https://www.youtube.com/watch?v=1qbTY5kMaic>), oficina de arte e de plantio de sementes nativas do cerrado (baru), sendo as atividades desenvolvidas de setembro a início de dezembro. Ao explorar o assunto, escolheu-se a história infantil a ser contada, tendo sido definido o livro "Azul e lindo planeta Terra, nossa casa", de Ruth Rocha e Otávio Roth, considerando o grau de assimilação das crianças e a linguagem mais adequada a ser trabalhada, assim como o cenário utilizado e demais recursos visuais.

Por fim, para obter indicadores acerca da percepção dos alunos, foi elaborado e aplicado aos alunos do $4^{\circ}$ ano das turmas $\mathrm{A}$ e $\mathrm{B}$, questionário com questões fechadas relacionadas ao meio ambiente, totalizando 42 respondentes, o que corresponde a $22 \%$ do total de alunos matriculados. A opção pelos alunos do $4^{\circ}$ ano para a produção de mudas e a aplicação do questionário se deu pelo total de alunos matriculados, além de apresentarem mais facilidade de leitura e compreensão das questões e por serem os responsáveis pelo plantio e manejo das mudas.

\section{Referencial Teórico}

\section{Educação Ambiental: marco legal}

O tema Educação Ambiental surgiu na década de 1970, decorrente de ações encabeçadas por organizações civis, estudiosos e interessados no assunto, que promoveram discussões acerca da problemática ambiental e de seus impactos sobre o planeta no presente e no futuro, instigados por catástrofes ambientais como a de Londres, em 1956, além dos efeitos nocivos do uso do DDT, descritos pela bióloga Rachel Charson, em 1962, entre outros episódios. Todavia, foi a partir das Conferências de Estocolmo e Tbilisi que a temática começou a ser abordada num contexto educativo e cidadão (ALBARDO; ALMEIDA, 2011).

No Brasil, o assunto torna-se relevante nos anos 1980 e 1990, com a instituição da Política Nacional do Meio Ambiente e com a Constituição Federal de 1988, cujo Capítulo VI trata sobre o Meio Ambiente, em seu art. 225, que estabelece: "Todos têm direito ao meio ambiente ecologicamente equilibrado, bem de uso comum do povo e essencial à sadia qualidade de vida, impondo-se ao Poder Público e à coletividade o dever de defendê-lo e preservá-lo para as presentes e futuras gerações". Informa, ademais, no inciso VI do parágrafo 1ํㅡ, 
como mecanismo para o Poder Público resguardar esse direito, "promover a Educação Ambiental em todos os níveis de ensino e a conscientização pública para a preservação do meio ambiente" (BRASIL, 2015).

Outro marco brasileiro na regulamentação e institucionalização da EA foi a Rio-92, que, por meio da Agenda 21, estabeleceu um guia de princípios e estratégias para a elaboração e a implementação de políticas públicas sustentáveis, constando na Dimensão da informação e do conhecimento no item 21:

\begin{abstract}
Promoção da capacitação e conscientização para a sustentabilidade. Trata de propostas relativas à internalização da questão ambiental nos hábitos e costumes da sociedade por meio da Educação Ambiental, e da capacitação para a sustentabilidade das instituições e atores sociais. (Grifos no original).
\end{abstract}

Segundo Silva e Leite (2008, p. 375), "a Agenda 21 Global, no capítulo 36 sugere a reorientação do ensino, no sentido de atingir o desenvolvimento sustentável'. Por sua vez, a Agenda 21 Goiás, alinhada à Agenda 21 nacional, contempla a valorização do capital humano, do conhecimento e da qualidade de vida: "Há graves carências educacionais, incompatíveis com o patamar de desenvolvimento do Estado. No entanto, com esforço próprio, e sempre em parceria com as experiências de vanguarda, é possível avançar no terreno da capacitação, da formação intensiva de recursos humanos [...]" (GOIÁS, 2006, p. 7).

O Ministério da Educação, em 1998, lançou os Parâmetros Curriculares Nacionais (PCN), visando a parametrizar os componentes curriculares a serem adaptados à realidade de cada município e especificidade de cada unidade escolar, explorado de forma multidisciplinar por referir-se a temas transversais como ética, pluralidade cultural, orientação sexual, entre outros. Segundo Narcizo (2009, p. 88):

Dentre várias formas possíveis de se trabalhar a Educação Ambiental, os Parâmetros Curriculares Nacionais (PCN's) afirmam ser a interdisciplinaridade essencial ao desenvolvimento de temas ligados ao Meio Ambiente, sendo necessário desfragmentar os conteúdos e reunir as informações dentro de um mesmo contexto, nas várias disciplinas.

Por meio da Lei no 9.795, institui-se a Política Nacional de Educação Ambiental, também reconhecida como Lei da Educação Ambiental, a qual dispõe, em seu art. $2^{\circ}$, que "[a] Educação Ambiental é um componente essencial e permanente da educação nacional, devendo estar presente, de 
forma articulada, em todos os níveis e modalidades do processo educativo, em caráter formal e não-formal". A Lei contempla, ainda, os princípios básicos e os objetivos fundamentais da Educação Ambiental, destacando a permanência do processo educativo, articulada às questões ambientais em diferentes esferas $e$ concepções pedagógicas que contribuem para o desenvolvimento de uma compreensão integrada e crítica.

Conforme estabelece a Lei, a EA deve permear todas as etapas do processo educativo, de forma direta (componente curricular obrigatório) e indireta, conforme elucidam França e Guimarães (2014, p. 3130): "a dimensão ambiental deve constar dos currículos de formação de professores, em todos os níveis e em todas as disciplinas".

\section{Educação Ambiental nas escolas}

A escola desempenha relevante função social, pois nela os indivíduos, além de terem acesso ao conhecimento científico, desenvolvem competências linguísticas e apreendem temas relacionados à organização das sociedades. Nesse sentido, a escola constitui-se ambiente de formação e informação de maneira complementar, além de contribuir para a construção de uma postura crítica e analítica da realidade socioambiental. De acordo com Mendonça (2007, p. 41), conceitualmente a EA é "um processo educativo que dialoga com valores éticos e regras políticas de convívio social, cuja compreensão permeia as relações de causas e efeitos dos elementos socioambientais numa determinada época, para garantir o equilíbrio vital dos seres vivos". Complementarmente, para Loureiro (2004) a EA consiste em evidenciar a essencialidade da relação entre vida e natureza no ambiente educativo, por meio de tendências pedagógicas e ambientalistas.

Dessa forma, promove-se a ampliação do entendimento sobre a EA em si, de tal modo que possa ser abordada contemplando aspectos sociais, políticos, éticos, econômicos e ecológicos que compõem a base para o desenvolvimento sustentável. Assim, as atividades pedagógicas na EA devem ter caráter interdisciplinar, perpassando conteúdos de diferentes disciplinas, ao mesmo tempo que estimulam o educando a voltar o olhar para a comunidade $e$ seus problemas. De acordo com Guimarães (2007), o processo educativo, no contexto socioambiental, deve extrapolar a mera transmissão tradicional do conhecimento; estimular a construção de novos saberes e proporcionar experiências em conformidade com os preceitos da sustentabilidade socioambiental.

Para Miranda (2007), é necessário ater-se a todas as atividades desenvolvidas no processo de EA por envolver pessoas, seus saberes e tradições, ao mesmo tempo que os conceitos sobre o tema são incorporados à formação do indivíduo. 
É uma relação com a vida das pessoas, o comportamento das pessoas, o jeito das pessoas. Quando se fala em educação, é bastante abrangente e se aplica também à Educação Ambiental: porque se está falando de vida e recursos que tocam a vida, de que pode haver paz dentro de um ambiente quando se consegue entender o papel, a função de cada elemento que faz parte de seu mundo. (MIRANDA, 2007, p. 191).

Segundo Vidal, Nogueira e Campos (2018), a operacionalização da EA transcende o espaço escolar, devendo envolver pais, familiares, poder público e comunidade escolar, de maneira macro, orientada sobre os impactos que os danos ambientais causam à coletividade, não devendo ser trabalhado de forma isolada. Ainda de acordo com os autores, a sistematização da EA deve considerar o indivíduo num contexto social, econômico, cultural e político em face da conscientização ambiental.

\section{Resultados e discussão}

O efetivo processo de conscientização ambiental congrega a participação dos diversos atores sociais para esclarecer e estabelecer uma relação harmoniosa entre 0 homem e a natureza. Assim, a Educação Ambiental é uma ferramenta importante para a transformação da coletividade.

Foi feita, para as crianças, uma apresentação prévia das atividades a serem desenvolvidas, assim como da problemática ambiental que permeia a sociedade contemporânea, ilustrada por situações como desmatamento, escassez hídrica, poluição do ar e das nascentes e seus impactos para a atual e as futuras gerações. Posteriormente, os alunos foram reunidos em ambiente comum para a contação de história (Figura 1). De acordo com Rodrigues (2008, p. 4), a figura do "Contador de Histórias" possibilita que "[...] ao preparar uma história para ser contada, tomamos a experiência do narrador e de cada personagem como nossa e ampliamos nossa experiência vivencial por meio da narrativa do autor".

Para Mateus et al. (2017), a utilização de instrumentos lúdicos, como a figura do "Contador de história" no processo de ensino, incita a imaginação e a criatividade, além de auxiliar na transmissão de valores sociais, especialmente ao considerarmos a importância da oralidade e da construção de narrativas na exposição de experiências e no processo de aprendizagem. "O ato de contar histórias é próprio do ser humano, e o professor pode apropriar-se dessa característica e transformar a contação em um importantíssimo recurso de formação do leitor" (PENNAC, 1993, p. 124 apud MATEUS et al., 2017, p. 57). 


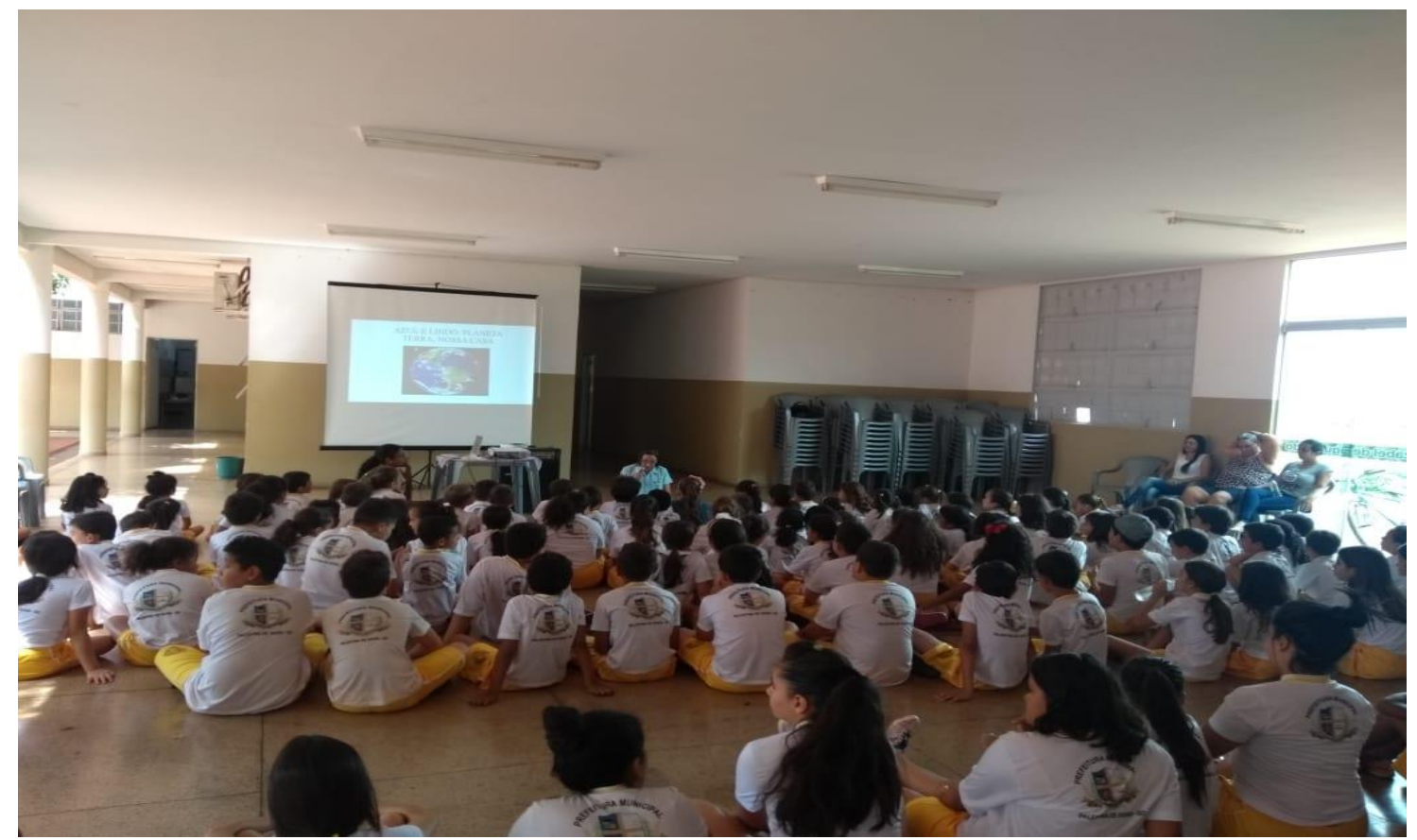

Figura 1: Atividade de contação de história e mostra de curta-metragem com alunos do turno vespertino da pré-escola ao $5^{\circ}$ ano.

Fonte: Dados da pesquisa (2019).

A dinâmica adotada possibilitou a integração entre os alunos de diferentes turmas e períodos e, consequentemente, a troca de conhecimento entre eles sobre as razões pelas quais se deve preservar o meio ambiente. Esses pontos foram abordados no livro que foi narrado enquanto imagens correlatas à temática eram projetadas aos alunos. Cabe destacar que, assim como presente no livro, o planeta foi apresentado como nossa casa, sendo feita uma analogia com os cuidados que temos no cotidiano com o nosso lar. Instigou-se, também, o pensar acerca de como nossas ações atuais podem e vão comprometer o futuro das próximas gerações, ou seja, a herança que deixamos. O livro foi inspirado na Declaração Mundial sobre o Meio Ambiente e nele é reforçada a necessidade de cuidados com o solo, com as florestas, com os recursos hídricos, com a fauna e com a flora, de maneira que o planeta continue lindo e azul.

Em um segundo momento, montou-se uma Oficina de arte infantil denominada "O futuro que eu desejo", momento em que os alunos foram divididos em grupos, formados conforme as turmas em que estavam matriculados e, individualmente, desenharam, em papel cartão, o que esperam do futuro, a partir do que assimilaram da mensagem do livro e na projeção de curta-metragem (Figura 2). Para a realização dessa oficina, as crianças receberam kits contendo lápis de cor, giz de cera e canetinhas, com porta-lápis feito com garrafa PET para estimular, nas crianças, práticas associadas aos 3 "Rs" (Reduzir, Reutilizar e Reciclar), ou seja, remeter à ideia de fazer reuso dos resíduos, no dia a dia. 


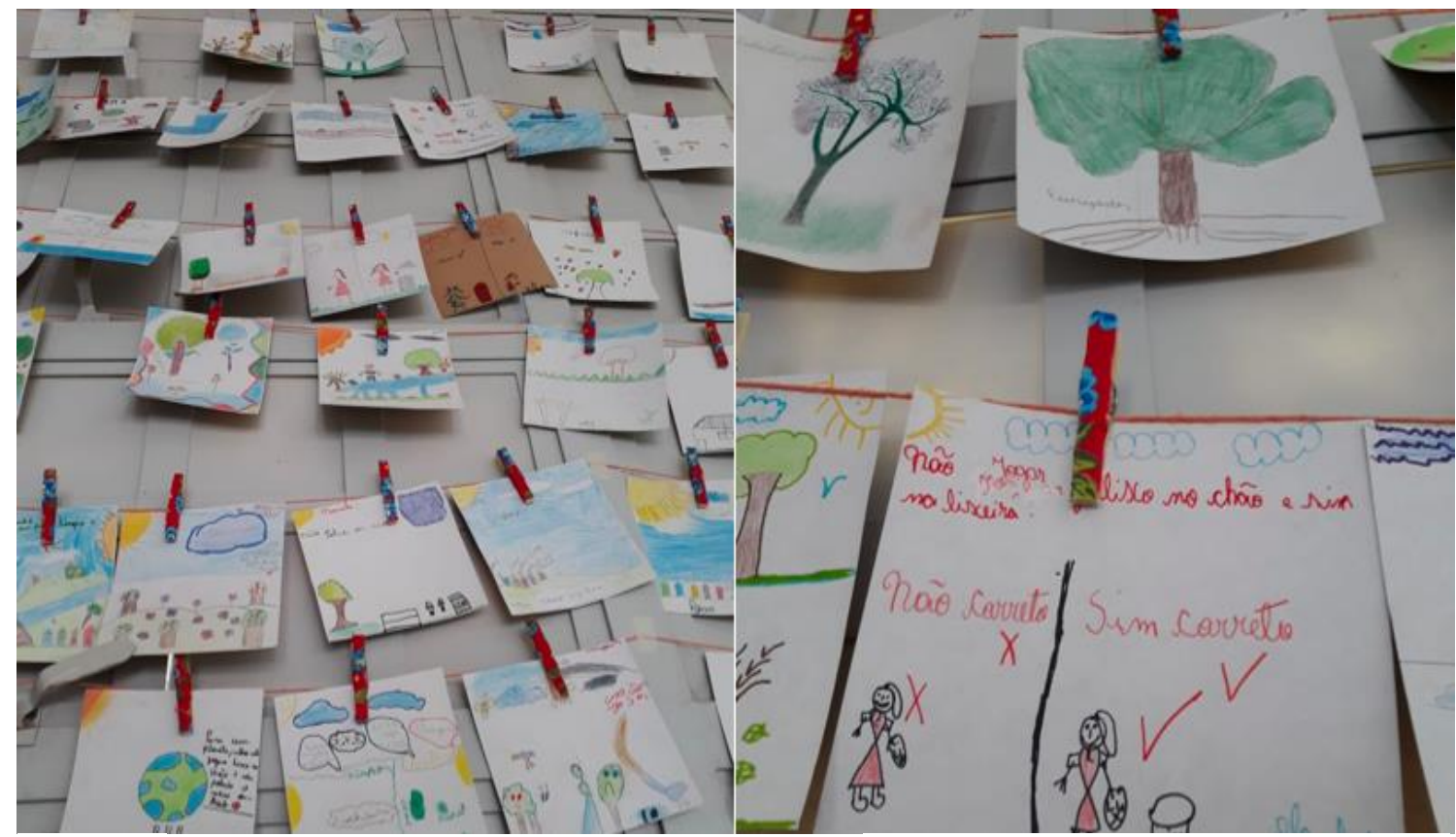

Figura 2: Oficina de arte infantil "Futuro que eu desejo", com alunos do turno vespertino da préescola ao 5 ano.

Fonte: Dados da pesquisa (2019).

Posteriormente, foi montado por eles um "varal" para exposição, em formato de literatura de cordel, dos desenhos criados, como ilustrado na Figura 3. Esse formato de atividade possibilitou que os alunos, além de exporem a própria ilustração, visualizassem as imagens produzidas pelos demais, sendo, portanto, mais um momento de troca e aprendizagem.

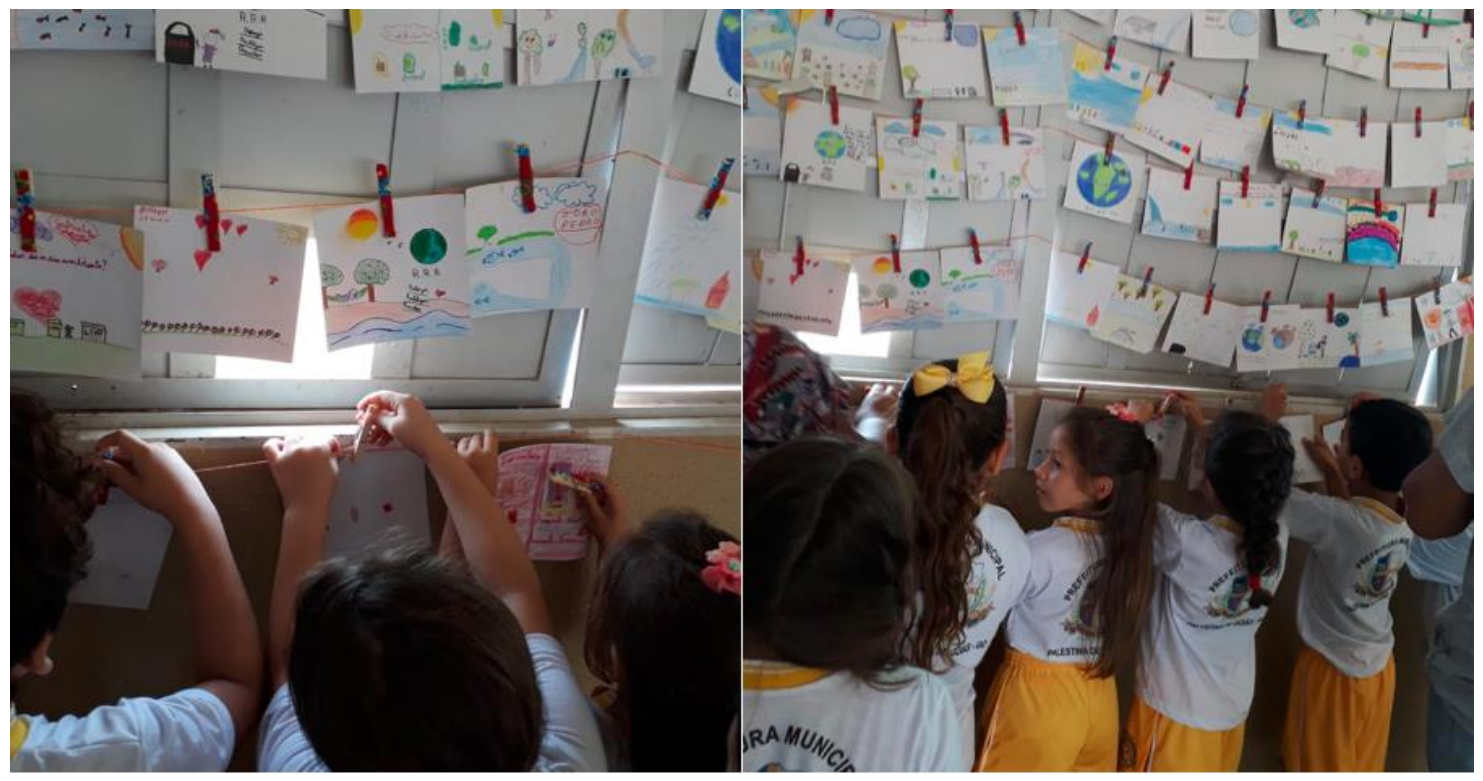

Figura 3: Montagem do "Varal de imagens".

Fonte: Dados da pesquisa (2019).

Revbea, São Paulo, v.16, № 1: 279-292, 2021. 
Outra atividade realizada durante a execução do projeto envolveu especificamente os alunos dos $4^{\text {os }}$ anos A e B para a produção de mais de 90 mudas de Baru, como ilustrado na Figura 4 . As turmas possuem um total de 20 e 22 alunos matriculados, respectivamente, dos quais 22 residem na zona urbana e 20 na zona rural. A escolha da cultura refere-se ao fato de ela ser nativa do bioma Cerrado e por ser possível encontrar facilmente sementes da espécie no município. Ademais, a comercialização da castanha do barueiro é de significativa importância econômica para os agricultores familiares. Foram usados sacos plásticos feitos de polietileno com furos para drenagem de água, cedidos pela Fazenda Escola do Instituto Federal Goiano, em Iporá-GO.

Os tratos culturais necessários à produção de mudas de Baru ficaram sob a responsabilidade dos alunos que, divididos em grupos e acompanhados pelo professor regente e membros do projeto, seguiram a orientação técnica 5 . De acordo com Albardo e Almeida (2011, s. p.), "no ensino normal é preciso que o professor saiba explorar os espaços existentes, tanto na escola como na comunidade ou no bairro onde se localiza a instituição educativa". Nessa perspectiva, objetivou-se de.spertar o senso de responsabilidade dos alunos.

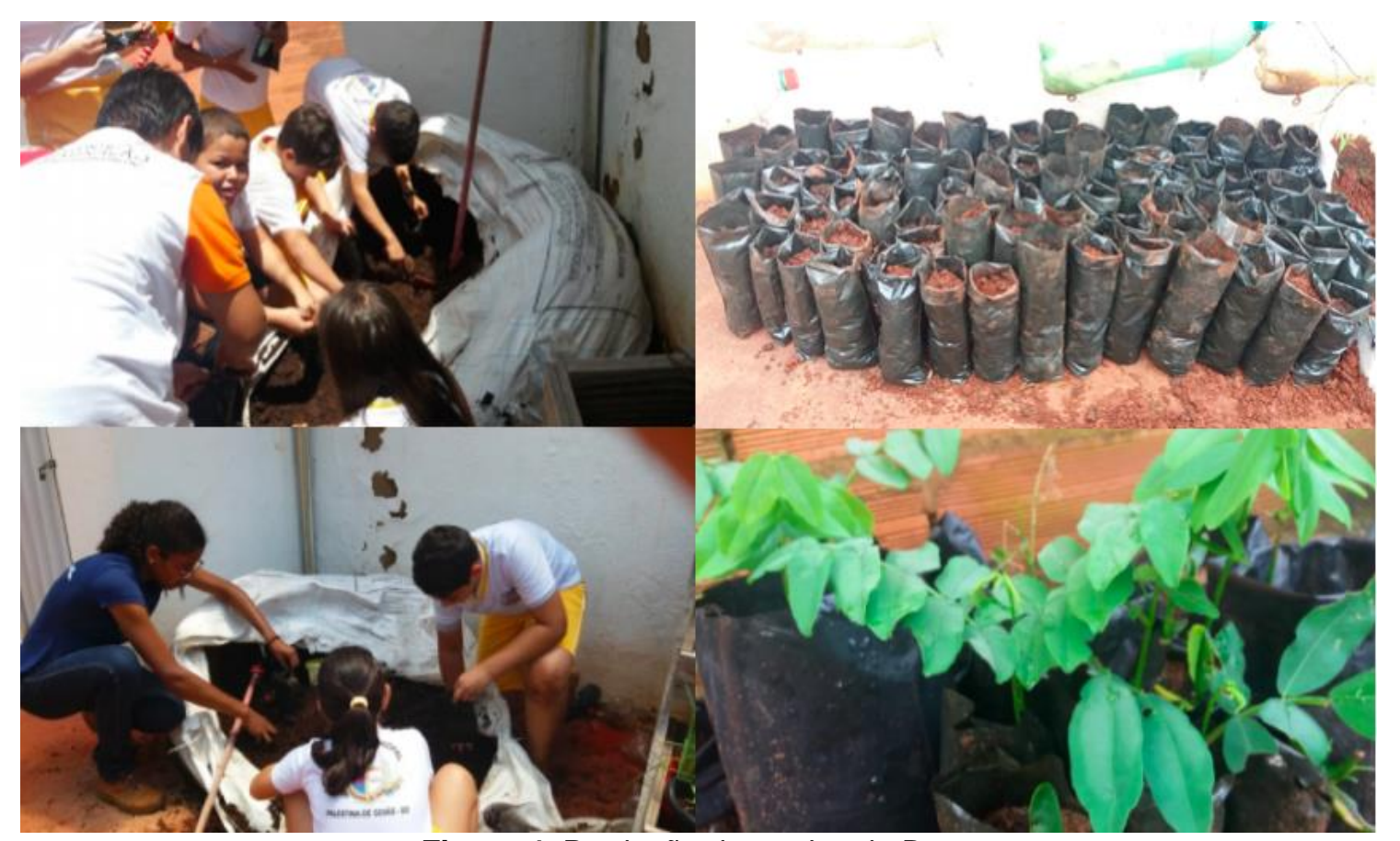

Figura 4: Produção de mudas de Baru. Fonte: Dados da pesquisa (2019).

5 conforme disponível em manual da Embrapa:< https://www.embrapa.br/cerrados/busca-depublicacoes/- publicacao/1042301/manual-de-viveiro-e-producao-de-mudas-especies-arboreasnativas-do-cerrado $>$. 
As sementes foram semeadas no mês de outubro, período em que as chuvas são mais frequentes. Os alunos foram organizados em cinco grupos, que se alternavam diariamente nos cuidados com as plantas, com o propósito de despertar uma consciência coletiva através de atividades dirigidas que impactassem no comportamento dos alunos. Concomitantemente, foram trabalhados temas diversos relacionados à problemática ambiental local, visando a verificar a percepção dos educandos sobre o que e como pode ser melhorado. A realização dessa atividade possibilitou a compreensão, por parte dos alunos, de que o cuidar do meio ambiente deve ser incorporado no dia a dia e de que pequenas atitudes são transformadoras.

Segundo descrito pelos alunos, as principais fontes de informação/aprendizagem sobre meio ambiente e temas correlatos acessíveis a eles são as veiculadas na mídia, principalmente as campanhas televisionadas e as feitas na escola. Constatou-se que, na unidade escolar, o assunto é tratado em atividades de produção de texto e em conteúdos da disciplina de Ciências, assim como em projetos como horta escolar e gincanas, caracterizando uma abordagem interdisciplinar. Para Vidal, Nogueira e Campos (2018, p. 72), "o processo de expansão da EA tem sido fundamental diante do contexto atual, portanto os atores responsáveis para essa disseminação encontram-se na escola, visto que é a base para a formação social [...]", ou seja, a escola figura como espaço vital para promover o conhecimento em EA.

No sentido de verificar se os alunos realizam atitudes rotineiras que contribuem para a preservação do meio ambiente, foi aplicado questionário com as indagações expostas no Quadro 1.

Quadro 1 - Questionário aplicado aos alunos do $4^{\circ}$ ano A e B.

\begin{tabular}{|l|c|c|}
\hline \multicolumn{1}{|c|}{ Questionamento realizado } & Sim & Não \\
\hline $\begin{array}{l}\text { Você acha que os dias mais quentes são provocados pelo } \\
\text { desmatamento? }\end{array}$ & $100 \%$ & \\
\hline Você joga papel no chão? & $1 \%$ & $99 \%$ \\
\hline $\begin{array}{l}\text { Quando você está escovando os dentes, você fecha a } \\
\text { torneira? }\end{array}$ & $99 \%$ & $1 \%$ \\
\hline $\begin{array}{l}\text { O lixo jogado fora de maneira errada prejudica (faz mal) a } \\
\text { natureza? }\end{array}$ & $100 \%$ & \\
\hline $\begin{array}{l}\text { A falta de água pode prejudicar a sobrevivência dos } \\
\text { homens e animais? }\end{array}$ & $98 \%$ & $2 \%$ \\
\hline Você acha que devemos cuidar do meio ambiente? & $100 \%$ & \\
\hline
\end{tabular}

Fonte: Elaborado pelos autores.

Conforme sinalizam as respostas, praticamente todos os alunos possuem conhecimento de atitudes que podem ser adotadas diariamente e que corroboram com a preservação do meio ambiente, assim como entendem a importância de "cuidarem" da natureza. Outras questões levantadas no questionamento verbal entre todos os alunos sobre a realidade local são exibidas no Quadro 2. 
Quadro 2 - Levantamento em grupo de questões associadas ao meio ambiente

\begin{tabular}{|l|l|}
\hline \multicolumn{1}{|c|}{ Pergunta } & \multicolumn{1}{c|}{ Respostas mais frequentes } \\
\hline Por que cuidar do meio ambiente? & $\begin{array}{l}\text { Porque é bom para o homem e os animais. } \\
\text { Porque é importante para nós. } \\
\text { Para a nossa sobrevivência. }\end{array}$ \\
\hline Como cuidar do meio ambiente? & $\begin{array}{l}\text { Jogar lixo no lixo. } \\
\text { Não colocar fogo nos lotes e no lixo. } \\
\text { Cuidar das árvores e dos rios. }\end{array}$ \\
\hline $\begin{array}{l}\text { Quais os principais problemas } \\
\text { ambientais da sua cidade? }\end{array}$ & $\begin{array}{l}\text { A falta de água. } \\
\text { Lixo nas ruas e nas estradas. } \\
\text { Muitas queimadas e fumaça. }\end{array}$ \\
\hline
\end{tabular}

Fonte: Elaborado pelos autores.

Verifica-se, a partir das respostas apresentadas, que os alunos compreendem a relação de dependência entre homem e natureza quando destacam que cuidar do meio ambiente resguarda a sobrevivência humana. Ademais, evidenciam problemas locais associados a questões ambientais, decorrentes de uma visão crítica. De acordo com Guimarães (2007), como pontos centrais no processo de educação e conscientização ambiental estão as práticas e reflexões que transformam a mentalidade do indivíduo, instigando-o a atuar em prol da sociedade no enfrentamento das questões socioambientais.

Cabe destacar que a EA, consoante previsto no art. $9^{\circ}$ da PNEA, deve contemplar todos os níveis de ensino formal, da educação básica à educação superior. Nesse sentido, a realização deste projeto promoveu uma interação entre gerações e alunos de diferentes modalidades e instituições de ensino, essencialmente direcionados para um objetivo comum: o respeito ao meio ambiente e a formação cidadã. Ademais, percebemos que o projeto tornou mais frequente as discussões sobre as questões ambientais em diferentes esferas - do local ao global -, possibilitando um espaço de diálogo e instigando o aprofundamento de estudos e ações que resguardam o meio ambiente e, consequentemente, a existência humana. Ressalta-se ainda que problemas dessa ordem não estão presentes apenas em grandes centros urbanos, o que reforça a importância do espaço escolar para o entendimento da relação de causa e efeito que envolve as questões ambientais e seus impactos sobre o próprio indivíduo e o outro.

\section{Conclusão}

O presente relato apresenta as atividades desenvolvidas de forma lúdica relacionadas à EA, para alunos do ensino fundamental, com o objetivo de "provocar" discussões que ressaltam o real valor do meio ambiente e a importância da comunidade como agente de transformação e preservação, através de sua forma de pensar e agir no ambiente no qual está inserida.

É importante considerar o papel das instituições de ensino, 
promoção do desenvolvimento sustentável, resguardando a preservação do meio ambiente no presente e no futuro, uma vez que cuidar do meio ambiente significa assegurar a sobrevivência da própria espécie humana. Assim sendo, a realização de projeto desta natureza, além de contemplar aspectos obrigatórios como interdisciplinaridade, proximidade da comunidade externa e associação entre teoria e prática, possibilita que as instituições de ensino verdadeiramente exerçam sua missão de contribuir para o despertar crítico-analítico do educando, em defesa dos recursos naturais e bens comuns.

\section{Agradecimentos} apoio financeiro.

\section{Referências}

ABRAMOVAY, R. Muito além da economia verde. 1. ed. São Paulo: Planeta Sustentável, 2012. 147 p.

ALBARDO, E. da C.; ALMEIDA, L. L. História da Educação Ambiental. Sabedoria política - um site dedicado ao estudo da política, 2011. Disponível em: <https://www.sabedoriapolitica.com.br/products/historia-daeduca\%C3\%A7\%C3\%A3o-ambiental/>.

BRASIL. Constituição da República Federativa do Brasil. 48. ed. Brasília: Câmara dos Deputados, Edições Câmara, 2015.

BRASIL. Presidência da República. Casa Civil. Subchefia para Assuntos Jurídicos. Lei n. 9.795, de 27 de abril de 1999. Dispõe sobre a Educação Ambiental, institui a Política Nacional de Educação Ambiental e dá outras providências. Diário Oficial [da] República Federativa do Brasil, Brasília, DF, n. 79, Seção 1, p. 1-3, 28 abr. 1999.

FRANÇA, P. A. R. de; GUIMARÃES, M. da G. V. Environmental education in Municipal Schools of Manaus: a case study from the perception of students. Revista Monografias Ambientais - REMOA, v.14, n.2, 2014, p. 3128 - 3138.

GERHARDT, T. E.; SILVEIRA, D. T. (orgs.). Métodos de pesquisa. Coordenado pela Universidade Aberta do Brasil - UAB/UFRGS e SEAD/UFRGS. Porto Alegre: Editora da UFRGS, 2009.

GOIÁS. Secretaria Municipal de Planejamento. Agenda 21 Goiás: Sustentabilidade do Desenvolvimento Econômico e Regional - "Bases para discussão". Goiânia: Seplan, 2006. 55p.

GUIMARÃES, M. Educação Ambiental: participação para além dos muros da escola. In: MELLO, S. S. de; TRAJBER, R. (org.). Vamos cuidar do Brasil: conceitos e práticas em Educação Ambiental na escola. Brasília: Ministério da Educação/Coordenação Geral de Educação Ambiental/Ministério do Meio Ambiente/Departamento de Educação Ambiental/Unesco, 2007. 
IBGE - Instituto Brasileiro de Geografia e Estatística. Sinopse do Censo Demográfico: municípios de Palestina de Goiás. Brasília: IBGE, 2019.

LOUREIRO, C. F. B. Educação Ambiental transformadora. In: LAYRARGUES, P. P. (coord.). Identidades da Educação Ambiental brasileira. Brasília: Ministério do Meio Ambiente, 2004.

MATEUS, A. et al. A importância da contação de história como prática educativa na educação infantil. Pedagogia em Ação, v. 5, n. 1, p. 54-69, 2013.

MEDEIROS, M. C. S.; RIBEIRO, M. da C. M.; FERREIRA, C. M. de A. Meio ambiente e Educação Ambiental nas escolas públicas. Disponível em: $<$ https://www.ambito-juridico.com.br>. Acesso em: 18 nov. 2017.

MENDONÇA, P. R. Políticas de formação continuada de professores(as) em Educação Ambiental no Ministério da Educação. In: MELLO, S. S. de; TRAJBER, R. (org.). Vamos cuidar do Brasil: conceitos e práticas em Educação Ambiental na escola. Brasília: Ministério da Educação/Coordenação Geral de Educação Ambiental/Ministério do Meio Ambiente/Departamento de Educação Ambiental/Unesco, 2007.

MIRANDA, X. Educação indígena: uma visão a partir do meio ambiente. In: MELLO, S. S. de; TRAJBER, R. (org.). Vamos cuidar do Brasil: conceitos e práticas em Educação Ambiental na escola. Brasília: Ministério da Educação/Coordenação Geral de Educação Ambiental/Ministério do Meio Ambiente/Departamento de Educação Ambiental/Unesco, 2007.

NARCIZO, K. R. dos S. Uma análise sobre a importância de trabalhar Educação Ambiental nas escolas. Revista Eletrônica Mestrado em Educação Ambiental, v. 22, janeiro a julho de 2009.

OLIVEIRA, G. C. S; TONIOSSO, J. P. Educação Ambiental: Práticas Pedagógicas na Educação Infantil. Cadernos de Educação: Ensino e Sociedade, São Paulo, v. 1, n. 1, p. 30-43, 2014.

RODRIGUES, E. B. T. Fundamentos teóricos práticos da Educação. Metodologia do Ensino Fundamental. 600ed.Goiânia: CEGRAF/UFG, 2008, v. v.1, p. 207-248.

SILVA, M. M. P. da; LEITE, V. D. Estratégias para realização de Educação Ambiental em escolas do ensino fundamental. Revista. Eletrônica do Mestrado em Educação Ambiental, v. 20, janeiro a junho de 2008.

VERDELONE, T. H.; CAMPBELL, G.; ALEXANDRINO, C. R. Trabalhando Educação Ambiental com turmas do ensino fundamental I. Brazilian Journal of Development, v.5, n.6, p.4675 - 4687, 2018.

VIDAL, D. B.; NOGUEIRA, M. T.; CAMPOS, T. S. Um caso de sucesso: metodologias que potencializam a Educação Ambiental no ensino fundamental. Revista Brasileira de Educação Ambiental, São Paulo, v. 13, n. 4, p. 66-78, 2018. 